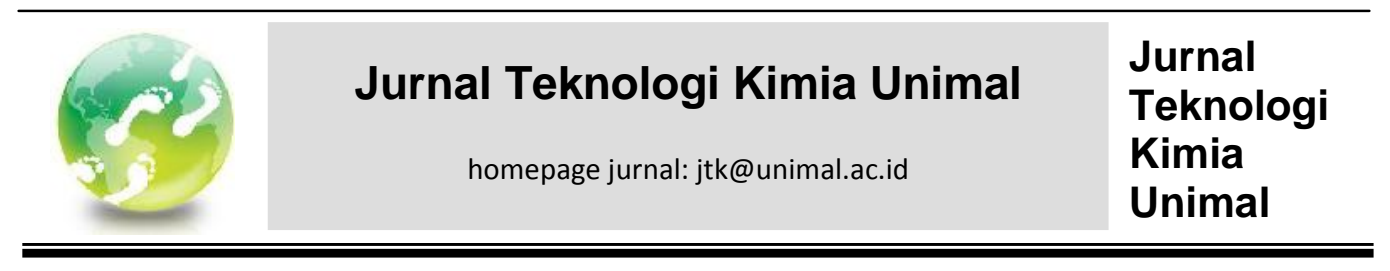

\title{
STUDI AWAL PRODUKSI BAHAN BAKAR DARI PROSES PIROLISIS KANTONG PLASTIK BEKAS
}

\author{
Nasrun, Eddy Kurniawan, Inggit Sari \\ Jurusan Teknik Kimia, Fakultas Teknik, Universitas Malikussaleh \\ J1. Batam No. 1 Bukit Indah, Blang Pulo, Lhokseumawe 24353 \\ Korespondensi: HP. 085260055045; e-mail: nasrun@unimal.ac.id
}

\begin{abstract}
ABSTRAK
Penggunaan sampah plastik sebagai bahan untuk menghasilkan bahan bakar minyak merupakan suatu alternatif yang dapat meningkatkan nilai ekonomis, disamping itu juga dapat menyelesaikan masalah lingkungan. Penelitian ini bertujuan untuk mengetahui kondisi operasi/proses terbaik pada pengolahan limbah kantong plastik jenis kresek menjadi bahan bakar. Proses pirolisis adalah dekomposisi kimia bahan organik melalui proses pemanasan tanpa atau sedikit oksigen dimana material mentah akan mengalami pemecahan stuktur kimia menjadi fase gas. Proses distilasi adalah proses pemisahan campuran dalam suatu larutan berdasarkan perbedaan titik didih. Variabel penelitian yang dilakukan meliputi waktu pirolisis selama $(15,30,45,60)$ menit, suhu pirolisis adalah $260^{\circ} \mathrm{C}, 270^{\circ} \mathrm{C}, 280^{\circ} \mathrm{C}, 290^{\circ} \mathrm{C}$ dan $300^{\circ} \mathrm{C}$. Pengujian terhadap bahan bakar minyak didasarkan pada standar mutu bahan bakar minyak di Indonesia yaitu nilai kalor, titik nyala (flash point), kadar abu, kadar air, analisa komposisi serta menentukan energi aktivasi (Ea). Hasil penelitian menunjukkan nilai kalor pembakaran sebesar $10.541,75 \mathrm{kkal} / \mathrm{kg}$, titik nyala (flash point) tetinggi pada suhu pirolisis $260^{\circ} \mathrm{C}$ waktu reaksi 15 menit $63,90 \mathrm{C}$, pada titik nyala terendah pada suhu pirolisis $300^{\circ} \mathrm{C}$ waktu reaksi 60 menit $57,5^{\circ} \mathrm{C}$, kadar abu tertinggi diperoleh pada suhu pirolisis $300^{\circ} \mathrm{C}$ waktu reaksi 60 menit yaitu $0,26 \%$ dan kadar abu terendah pada suhu pirolisis $260^{\circ} \mathrm{C}$ waktu reaksi 15 menit yaitu $0,01 \%$, kadar air terbaik diperoleh pada suhu pirolisis $300^{\circ} \mathrm{C}$ waktu reaksi 60 menit yaitu $0,01 \%$. Hasil pengujian analisa komposisi menunjukkan persentase terbanyak adalah $\mathrm{C}_{12} \mathrm{H}_{24}$ yaitu sebesar $29,3 \%$, nilai aktivasi energi yang didapat adalah $10.106,77 \mathrm{kj} / \mathrm{mol}$.
\end{abstract}

Kata kunci: pirolisis, nilai kalor, titik nyala (flash point), kadar abu, kadar air, analisa komposisi, energi aktivasi

\section{Pendahuluan}

Pengolahan sampah plastik sebagai salah satu pengembangan dari ilmu pengetahuan, memberikan manfaat positif untuk mengatasi masalah lingkungan, 
serta menjadi tawaran solusi bahan bakar alternatif. Konversi yang dihasilkan dari proses ini mencapai $60 \%$ bahkan lebih tergantung dari bahan plastik yang digunakan dengan penambahan zat kimia lain. Plastik juga merupakan bahan anorganik buatan yang tersusun dari bahan-bahan kimia yang cukup berbahaya bagi lingkungan. Sampah plastik sangatlah sulit untuk diuraikan secara alami, untuk menguraikan sampah plastik membutuhkan kurang lebih 80 tahun agar dapat terdegradasi secara sempurna. Saat ini jumlah sampah yang terdata tiap harinya yang masuk di Kota Lhokseumawe sekitar 243 m3/hari yang terbuang siasia (Badan Lingkungan Hidup Kota, 2014).

Penggunaan bahan bakar minyak yang semakin meningkat seiring dengan pertambahan penduduk dan pertumbuhan industri. Hal ini menuntut suatu pemikiran dan gagasan untuk menggali serta mengembangkan potensi sumbersumber energi alternatif, terlebih dengan semakin menipisnya cadangan minyak dunia (bahan bakar fosil) yang terbatas cadangannya, maka perlu untuk merintis penggunaan energi alternatif (terbarukan). Maka dari itu penggunaan sampah kantong plastik jenis kresek untuk bahan pengolahan bahan bakar sebagai bahan bakar alternatif pada penelitian ini sedikit lebih efektif untuk menanggulangi masalah krisis energi dan sampah kantong plastik jenis kresek yang hanya terbuang sia-sia (Hadiwiyoto, 2000).

Beberapa penelitian mengenai pengolahan bahan bakar minyak telah dilakukan. Aprian Ramadhan (2012) melakukan penelitian pengolahan sampah plastik jenis High Density Polyethylene (HDPE) dan Low Density Polyethylene (LDPE) menjadi minyak menggunakan proses pirolisis, untuk plastik jenis High Density Polyethylene (HDPE) banyak sampah digunakan 500 gram waktu operasi 60 menit terjadi pada suhu $400 \mathrm{oC}$ didapat jumlah produk sebanyak $43,1 \%$. untuk plastik jenis Low Density Polyethylene (LDPE) banyak sampah digunakan 500 gram waktu operasi 60 menit terjadi pada suhu $400 \mathrm{oC}$ didapat jumlah produk sebanyak $42,3 \%$.

Kadir (2012) melakukan penelitian kajian pemanfaatan sampah plastik sebagai sumber bahan bakar cair. Percobaan I digunakan plastik jenis kantong 
kresek banyak sampah digunakan 500 gram waktu operasi 30 menit suhu pirolisis $300^{\circ} \mathrm{C}$ didapat jumlah produk sebanyak $40,7 \%$. Percobaan II digunakan HDPE jenis botol oli banyak sampah digunakan 500 gram waktu operasi 25 menit suhu piroisis $415^{\circ} \mathrm{C}$ didapat jumlah produk sebanyak 38\%. Percobaan III digunakan botol aqua PET (Polypropylene Terephtalate) banyak sampah digunakan 500 gram waktu operasi 20 menit suhu piroisis $400^{\circ} \mathrm{C}$ didapat jumlah produk sebanyak $42,9 \%$.

Umuri (2014) melakukan penelitian karakterisasi bahan bakar dari sampah plastik jenis high density polyethylene dan low density polyethylene. Hasil penelitian untuk bahan bakar dari sampah plastik jenis high density polyethylene menunjukkan pada suhu pirolisis $480^{\circ} \mathrm{C}$ yield yang dihasilkan seberat 59,4\% . untuk bahan bakar dari sampah plastik low density polyethylene menunjukkan pada suhu pirolisis $480^{\circ} \mathrm{C}$ yield yang dihasilkan seberat $59,7 \%$, nilai kalor sebesar $10.814,829 \mathrm{kkal} / \mathrm{kg}$ untuk minyak dari plastik HDPE dan 10.674,728 kkal/kg untuk minyak dari plastik LDPE, untuk plastik jenis HDPE titik nyala tertinggi diperoleh sebesar $60,5^{\circ} \mathrm{C}$ pada suhu pirolisis $400^{\circ} \mathrm{C}$ untuk plastik jenis LDPE diperoleh pada suhu pirolisis terendah $400^{\circ} \mathrm{C}$ yaitu sebesar $59,4^{\circ} \mathrm{C}$. bahan bakar minyak dari sampah plastik jenis plastik HDPE kadar abu yang diperoleh paling banyak adalah pada suhu pirolisis tertinggi $480^{\circ} \mathrm{C}$ yaitu $0,3 \%$ plastik jenis LDPE juga terjadi hal yang sama, kadar abu yang diperoleh paling banyak adalah pada suhu pirolisis tinggi $460^{\circ} \mathrm{C}$ yaitu $0,22 \%$.

Beberapa penelitian mengenai pengolahan bahan bakar minyak telah dilakukan. Oleh karena itu perlu dicari kondisi operasi/proses terbaik yang berbeda dari penelitian diatas serta pada alat pirolisis digunakan katalis berbentuk ball (bola keramik) yang berfungsi sebagai adsorben (penyerap) dan kondenser (pendingin), serta menganalisa nilai kalor, titik nyala (flash point), kadar abu, kadar air dan analisa komposisi pada minyak yang dihasilkan dari limbah kantong plastik jenis kresek. 
Tujuan penelitian ini adalah menentukan kondisi operasi/proses terbaik dalam proses pirolisis limbah kantong plastik jenis kresek, menganalisa pengaruh suhu dan waktu pada proses pirolisis, menganalisa nilai kalor, titik nyala (flash point), kadar abu, kadar air dan analisa komposisi pada minyak yang dihasilkan dari limbah kantong plastik jenis kresek serta menentukan energi aktivasi.

Adapun manfaat dari penelitian ini adalah memanfaatkan limbah kantong plastik jenis kresek untuk diolah sebagai bahan bakar. Pengolahan sampah plastik jenis kresek menjadi bahan bakar mempunyai prospek yang cerah serta sangat menguntungkan karena bahan baku yang mudah didapat dan berlimpah juga memberikan kontribusi dari segi penerapan teknologi untuk mendukung kebijakan pengembangan energi alternatif, yang berbasis dari sampah non-biodegradeble yaitu sampah plastik jenis kresek dan menumbuhkan swasembada energi sehingga diharapkan dapat membantu menanggulangi krisis energi akibat berkurangnya cadangan minyak mentah yang berasal dari fosil. Penelitian ini akan terfokus pada pemanfaatan limbah sampah plastik jenis kresek untuk diolah menjadi bahan bakar minyak dengan suhu yang digunakan untuk proses pirolisis adalah $260^{\circ} \mathrm{C}$, $270^{\circ} \mathrm{C}, 280^{\circ} \mathrm{C}, 290^{\circ} \mathrm{C}$ dan $300^{\circ} \mathrm{C}$ dan waktu pirolisis selama $15,30,45$, dan 60 menit.

Plastik adalah istilah umum bagi polimer yaitu material yang terdiri dari rantai panjang karbon dan elemen-elemen lain (oksigen, nitrogen, klorin atau belerang) yang mudah dibuat menjadi berbagai bentuk dan ukuran. Bahan pembuat plastik pada mulanya adalah minyak dan gas sebagai sumber alami, tetapi di dalam perkembangannya bahan-bahan ini digantikan dengan bahan sintesis sehingga dapat diperoleh sifat-sifat plastik yang diinginkan. Komponen utama plastik sebelum membentuk polimer adalah monomer yang merupakan bagian atau rantai paling pendek menyusun dan membentuk bahan-bahan dasar plastik (monomer) secara sambung-menyambung. Plastik juga mengandung zat nonplastik yang disebut aditif. Zat aditif diperlukan untuk memperbaiki sifat plastik itu sendiri. Bahan aditif untuk plastik diantaranya berfungsi sebagai pewarna, antioksidan, penyerap cahaya ultraviolet, penstabil panas, penurun 
viskositas, penyerap asam, pengurai peroksida, pelumas, peliat dan lain-lain (Anonimous, 2005).

Menurut data Kementerian Lingkungan Hidup di seluruh Indonesia ada 176 ribu ton sampah pertahun. Sebanyak $15 \%$ di antaranya adalah sampah plastik hitam. Berdasarkan asalnya sampah (padat) dapat digolongkan sebagai sampah biodegradable yaitu sampah yang terdiri dari bahan-bahan penyusun tumbuhan dan hewan yang diambil dari alam atau dihasilkan dari kegiatan pertanian, perikanan atau yang lainnya. Sampah ini dengan mudah diuraikan dalam proses alami dengan bantuan mikroba di alam. Sampah rumah tangga sebagian besar sampah organik, yang termasuk sampah organik misalnya sampah dari dapur, sisa tepung, sayuran, kulit buah dan daun. Sampah non-biodegradeble yaitu, sampah yang tidak mudah terurai di alam seperti mineral dan minyak bumi atau dari proses industri. (Hadiwiyoto, 1983).

Sampah plastik jenis kresek termasuk sampah yang non-biodegradable yang tidak mudah terurai dan memerlukan waktu yang lama. Material plastik banyak digunakan karena memiliki kelebihan dalam sifatnya yang ringan, transparan, tahan air serta harganya relatif murah dan terjangkau oleh semua kalangan masyarakat. Segala keunggulan ini membuat plastik digemari dan banyak digunakan dalam hampir setiap aspek kehidupan manusia. Akibatnya jumlah produk plastik yang akan menjadi sampah pun terus bertambah. Kantongkantong plastik jenis kresek ini tidak mudah terurai sehingga hanya akan terus menumpuk dan bertambah di TPA sampai 1000 tahun ke depan (Febrianto dkk, 2001).

Pengembangan proses pengolahan sampah plastik dilakukan melalui eksperimentasi untuk membuka peluang pemanfaatan sampah plastik dengan penerapan teknologi sederhana, murah, dan nyata. Eksperimen juga mencakup eksplorasi sifat dan karakteristik kantong plastik yang unik untuk diaplikasikan menjadi produk bernilai tinggi sehingga dapat menaikkan nilai dari sampah kantong plastik. Selain itu dapat diminimalisir dengan menggunakan kembali 
kantong plastik yang disimpan di rumah, secara tidak langsung kita telah mengurangi sampah plastik yang dapat terbuang percuma setelah digunakan bahkan lebih bagus lagi jika dapat didaur ulang plastik menjadi sesuatu yang lebih berguna (recycle). Pemanfaatan sampah plastik merupakan upaya menekan pembuangan plastik seminimal mungkin dan dalam batas tertentu menghemat sumber daya dan mengurangi ketergantungan bahan baku impor. Pemanfaatan sampah plastik dapat dilakukan dengan pemakaian kembali (reuse) maupun daur ulang (recycle).

Pemanfaatan sampah plastik dengan cara daur ulang umumnya dilakukan oleh industri. Secara umum terdapat empat persyaratan agar suatu sampah plastik dapat diproses oleh suatu industri, antara lain sampah harus dalam bentuk tertentu sesuai kebutuhan (biji, pellet, serbuk, pecahan) sampah harus homogen, tidak terkontaminasi, serta diupayakan tidak teroksidasi. Untuk mengatasi masalah tersebut, sebelum digunakan sampah plastik diproses melalui tahapan sederhana, yaitu pemisahan, pemotongan, pencucian, dan penghilangan zat-zat seperti besi dan sebagainya, klasifikasi plastik menurut struktur, kimianya terbagi atas dua macam yaitu linear dan jaringan tiga dimensi.

Bila monomer membentuk rantai polimer yang lurus (linear) maka akan terbentuk plastik thermoplastik yang mempunyai sifat meleleh pada suhu tertentu, melekat mengikuti perubahan suhu dan sifatnya dapat balik (reversible) kepada sifatnya yakni kembali mengeras bila didinginkan. Bila monomer berbentuk tiga dimensi akibat polimerisasi berantai akan terbentuk plastik thermosetting dengan sifat tidak dapat mengikuti perubahan suhu (irreversible). Bila sekali pengerasan telah terjadi maka bahan tidak dapat dilunakkan kembali.

Secara umum, plastik dapat digolongkan ke dalam dua golongan yaitu termoseting dan termoplastik. Termoseting merupakan jenis plastik yang tidak bisa didaur-ulang atau dicetak lagi. Pemanasan ulang akan menyebabkan kerusakan molekul-molekul penyusunnya. Termoseting tidak dapat mengikuti perubahan suhu (irreversibel) bila sekali pengerasan telah terjadi maka bahan 
tidak dapat dilunakkan kembali. Pemanasan yang tinggi tidak akan melunakkan termoseting melainkan akan membentuk arang dan terurai. Plastik jenis termoseting tidak begitu menarik dalam proses daur ulang karena selain sulit penanganannya juga volumenya jauh lebih sedikit.

Termoplastik merupakan jenis plastik yang bisa didaur ulang atau dicetak lagi dengan proses pemanasan ulang berdasarkan sifat-sifatnya terhadap perubahan suhu termoplastik meleleh pada suhu tertentu, melekat mengikuti perubahan suhu dan mempunyai sifat dapat balik (reversibel) kepada sifat aslinya, yaitu kembali mengeras bila didinginkan.

Kantong plastik jenis kresek ternyata mengandung minyak bila dipanaskan melalui proses perengkahan kemudian didistilasi plastik bisa menjadi bahan bakar minyak. Namun, itu bergantung pada jenis plastiknya. Plastik yang bisa disuling antara lain plastik polietilena (PE), polypropylene carbonate (PPC), polyethylene terephthalate (PET), density polyethylene (DPE), dan low-density polyethylene (LDPE). Penggunaan sampah plastik jenis kresek sebagai bahan untuk membuat bahan bakar minyak yang berangkat dari keprihatinan bahwa, semakin hari jumlah produksi sampah semakin banyak serta ternyata di kota besar justru menimbulkan permasalahan yang berat dan berkepanjangan dan tentunya semua kota yang berkembang akan menghadapi permasalahan ini.

Memang upaya penggunaan sampah plastik sebagai bahan bakar tidak akan dapat menyelesaikan permasalahan sampah harus diselesaikan secara integralistik dari beberapa faktor, namun upaya ini merupakan salah satu cara untuk mengurangi produksi sampah plastik jenis kresek. Sebagian besar plastik yang digunakan masyarakat merupakan jenis kantong plastik jenis kresek. Plastik tersebut dipanaskan untuk menghasilkan gas selanjutnya gas didinginkan untuk menghasikan minyak, gas dan karbon. Sistem proses plastik secara tepat ternyata dapat menghasilkan minyak olahan plastik yang tak kalah mutunya dengan bahan bakar minyak yang ada dipasaran, namun tidak semua plastik dapat diolah (secara optimal) menjadi minyak seperti PET, PVC dan PS 


\section{Bahan dan Metode}

Pada penelitian ini dilakukan tiga tahap proses penelitian, yaitu persiapan bahan baku sesuai dengan varian, tahap pembuatan, dan analisis terhadap produk baik secara fisika maupun kimia. Tahap pembuatan ialah proses produksi bahan bakar yaitu dari limbah kantong plastik jenis kresek dengan menggunakan metode pirolisis dan tahap analisis adalah tahap menganalisa nilai kalor, titik nyala (flash point), kadar abu, kadar air dan analisa komposisi yang terkandung dalam produk bahan bakar.

Untuk kelancaran dalam melakukan penelitian ini maka dibutuhkan beberapa peralatan dan bahan yang mendukung. Alat yang digunakan dalam penelitian ini adalah dapur pirolisis sebagaimana terlihat dalam Gambar 1.

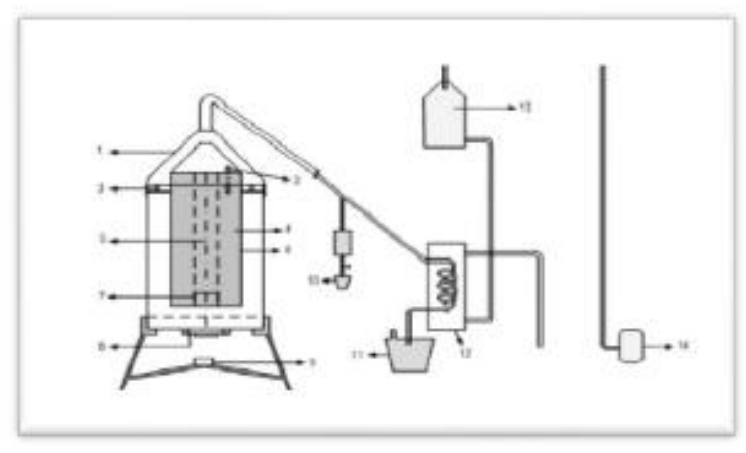

Gambar 1 Dapur pirolisis

Keterangan Gambar 1:
1. Penutup
8. Saluran udara
2. Dudukan termokopel
9. Tempat abu pembakaran awal
3. Lubang asap
10. Penampung tar
4. Ruang perengkahan
11. Penampung bahan bakar
5. Cerobong dalam
12. Condenser
6. Ruang pembakaran
13. Bak air
7. Pembakaran awal
14. Pompa air. 
Di samping dapur pirolisis juga digunakan peralatan pendukung lainnya seperti alat distilasi, GC-MS, centrifuge, dan lain-lain. Adapun bahan-bahan yang digunakan adalah kantong plastik kresek bekas dan katalis bola keramik. Analisa hasil penelitian berupa analisa nilai kalor, titik nyala (flash point), kadar abu, kadar air, dan analisa komposisi.

Sampah kantong plastik jenis kresek kering seberat 500 gram dimasukkan ke dalam tempat umpan reaktor pirolisis. Kemudian pemanas reaktor dijalankan sesuai dengan variasi suhu dan waktu pemanasan yang telah ditentukan yaitu 15 , 30, 45, dan 60 menit. Operasi diulangi untuk suhu pemanasan yang telah divariasikan yaitu $260^{\circ} \mathrm{C}, 270^{\circ} \mathrm{C}, 280^{\circ} \mathrm{C}, 290^{\circ} \mathrm{C}$ dan $300^{\circ} \mathrm{C}$. Hasil yang diperoleh ditampung pada wadah penampungan untuk kemudian didistilasi. Cairan yang mengandung impuritis dan bahan bakar didistilasi dengan suhu $115^{\circ} \mathrm{C}$ hingga diperoleh bahan bakar minyak. Kemudian hasil yang diperoleh dianalisa nilai kalor, titik nyala (flash point), kadar abu, kadar air, dan analisa komposisi.

\section{Hasil Dan Diskusi}

\subsection{Nilai kalor bahan bakar minyak}

Nilai kalori adalah suatu angka yang menyatakan jumlah panas/kalor yang dihasilkan dari proses pembakaran bahan bakar dengan udara/oksigen. Nilai kalor diperlukan karena dapat digunakan untuk menghitung jumlah konsumsi bahan bakar minyak yang dibutuhkan untuk suatu mesin atau suatu periode. Pengukuran panas pembakaran dapat dikerjakan dengan berbagai metoda, yaitu Gas Chromatography (GC), Aniline Gravity Product (AGP ASTM D-1405), dan Bomb Calorimeter (ASTM D-240). Panas pembakaran adalah jumlah panas yang dihasilkan apabila bahan bakar dibakar pada kondisi ideal dan dinyatakan dalam BTU/lb, kkal/kg atau BTU/USG.

Pada penelitian ini nilai kalor bahan bakar minyak dari limbah kantong plastik jenis kresek dihitung berdasarkan komposisi kimia dari hasil analisa GCMS. Berdasarkan dari hasil perhitungan komposisi kimia pada bahan bakar minyak, maka nilai kalor yang diperoleh untuk kantong plastik jenis kresek yaitu 
sebesar $10.541,75 \mathrm{kkal} / \mathrm{Kg}$. Nilai kalor yang diperoleh pada plastik jenis kresek tidak jauh berbeda dan sesuai dengan standar mutu nilai kalor bahan bakar minyak pada umumnya yaitu $10.160-11.000 \mathrm{kkal} / \mathrm{kg}$ (Syafari, 2011).

\subsection{Pengaruh suhu dan waktu pirolisis terhadap titik nyala (flash point)}

Titik nyala (flash point) adalah titik temperatur terendah dimana bahan bakar dapat menyala pada kondisi tertentu pada tekanan satu atmosfer. Titik nyala (flash point) merupakan faktor penting untuk keamanan terhadap kebakaran. Penentuan nilai titik nyala ini juga berkaitan dengan keamanan dalam penyimpanan penanganan bahan bakar dan diuji dengan menggunakan alat Pensky Marten Closed Tester (ASTM, 1990). Hubungan antara suhu dan waktu pirolisis terhadap titik nyala (flash point) pada bahan bakar minyak untuk plastik jenis kresek dapat dilihat dalam Gambar 2.

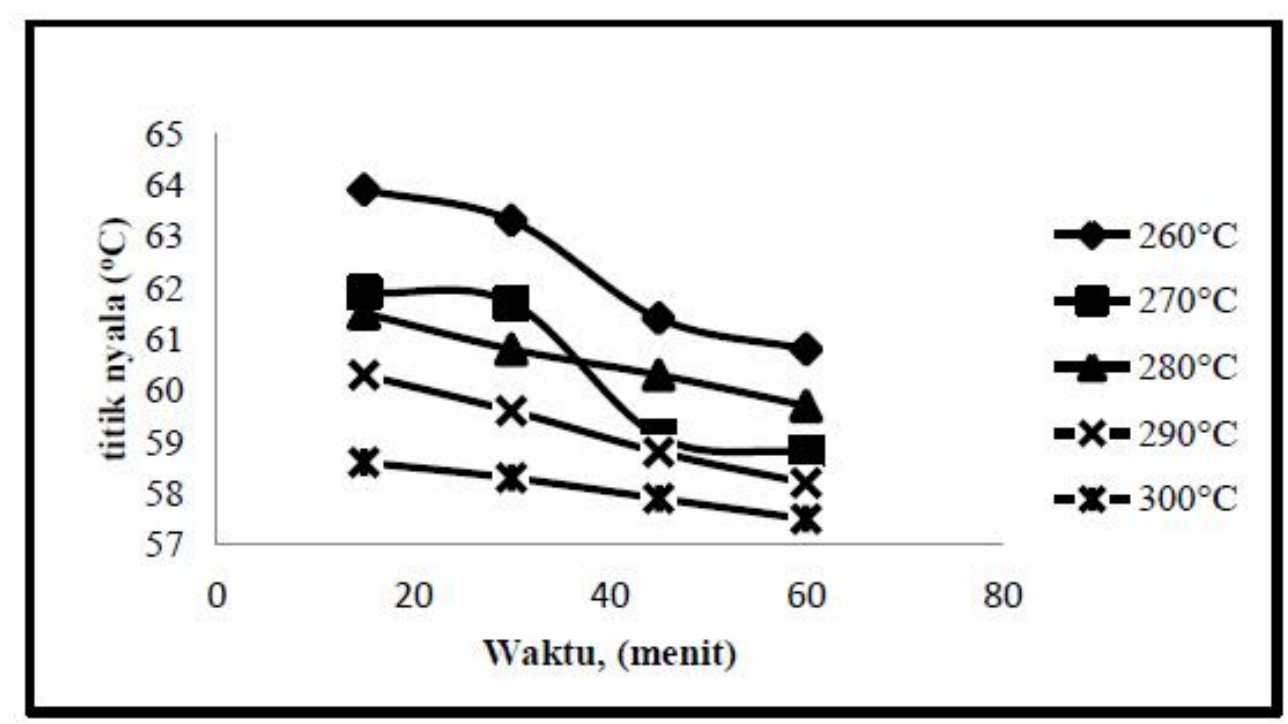

Gambar 2 Pengaruh suhu dan waktu pirolisis terhadap titik nyala (flash point)

Gambar 2 menunjukkan bahwa untuk suhu pirolisis $260^{\circ} \mathrm{C}$ waktu reaksi 15 menit titik nyala tertinggi diperoleh sebesar $63,9^{\circ} \mathrm{C}$, suhu pirolisis $260^{\circ} \mathrm{C}$ waktu reaksi 30 menit titik nyala diperoleh sebesar $63,3^{\circ} \mathrm{C}$, waktu reaksi 45 menit titik nyala diperoleh sebesar $61,4^{\circ} \mathrm{C}$ dan pada waktu reaksi 60 menit titik nyala diperoleh sebesar $60,8^{\circ} \mathrm{C}$. Suhu pirolisis $270^{\circ} \mathrm{C}$ pada waktu reaksi 15 menit titik nyala diperoleh sebesar $61,9^{\circ} \mathrm{C}$ waktu reaksi 30 menit titik nyala diperoleh sebesar 
$61,7^{\circ} \mathrm{C}$, waktu reaksi 45 menit titik nyala diperoleh sebesar $59,1^{\circ} \mathrm{C}$ dan pada waktu reaksi 60 menit titik nyala diperoleh sebesar $58,8^{\circ} \mathrm{C}$. Suhu pirolisis $280^{\circ} \mathrm{C}$ waktu reaksi 15 menit titik nyala diperoleh sebesar $61,5^{\circ} \mathrm{C}$, waktu reaksi 30 menit titik nyala diperoleh sebesar $60,8^{\circ} \mathrm{C}$, waktu reaksi 45 menit titik nyala diperoleh sebesar $60,3^{\circ} \mathrm{C}$ dan waktu reaksi 60 menit titik nyala diperoleh sebesar $59,7^{\circ} \mathrm{C}$. Suhu pirolisis 290 oC waktu reaksi 15 menit titik nyala diperoleh sebesar $60,3^{\circ} \mathrm{C}$, waktu reaksi 30 menit titik nyala diperoleh sebesar $59,6^{\circ} \mathrm{C}$, waktu reaksi 45 menit titik nyala diperoleh sebesar $58,8^{\circ} \mathrm{C}$ dan pada waktu reaksi 60 menit titik nyala terendah diperoleh sebesar $58,2^{\circ} \mathrm{C}$.

Suhu pirolisis $300^{\circ} \mathrm{C}$ waktu reaksi 15 menit titik nyala diperoleh sebesar $58,6^{\circ} \mathrm{C}$, waktu reaksi 30 menit titik nyala diperoleh sebesar $58,3^{\circ} \mathrm{C}$, waktu reaksi 45 menit titik nyala diperoleh sebesar $57,9^{\circ} \mathrm{C}$ dan waktu reaksi 60 menit titik nyala terendah diperoleh sebesar $57,5^{\circ} \mathrm{C}$. Hal ini disebabkan oleh semakin tinggi suhu pirolisis, maka semakin cepat pula api menyambar ketika disulut karena dipengaruhi oleh kandungan air dalam minyak. Menurut Tjokrowisastro dkk (1990), semakin tinggi suhu pirolisis maka semakin sedikit kandungan air dalam minyak tersebut sehingga api cepat menyambar dan titik nyala yang diperoleh semakin kecil.

\subsection{Pengaruh suhu dan waktu pirolisis terhadap kadar abu}

Abu adalah zat organik sisa hasil pembakaran suatu bahan organik. Kadar abu merupakan bagian berat dari bahan yang didasarkan atas berat keringnya. Kadar abu merupakan sifat fisis bahan bakar yang menunjukkan banyaknya residu yang terdapat dalam bahan bakar yang dinyatakan dalam persen. Gambar hasil pengujian kadar abu untuk bahan bakar minyak dari limbah kantong plastik jenis kresek ditunjukkan pada Gambar 3.

Gambar 3 menunjukkan bahwa kadar abu paling tinggi diperoleh pada suhu pirolisis $300^{\circ} \mathrm{C}$ waktu reaksi 60 menit yaitu $0,26 \%$ dan kadar abu paling rendah pada suhu pirolisis $260^{\circ} \mathrm{C}$ waktu reaksi $15-30$ menit yaitu 0,01\%. Kadar abu merupakan sifat fisis bahan bakar yang menunjukkan banyaknya residu yang terdapat dalam bahan bakar, banyaknya persen residu yang terdapat dibahan bakar 
minyak menunjukkan tidak baiknya suatu proses penggolahan, serta sebagai parameter nilai pada bahan.

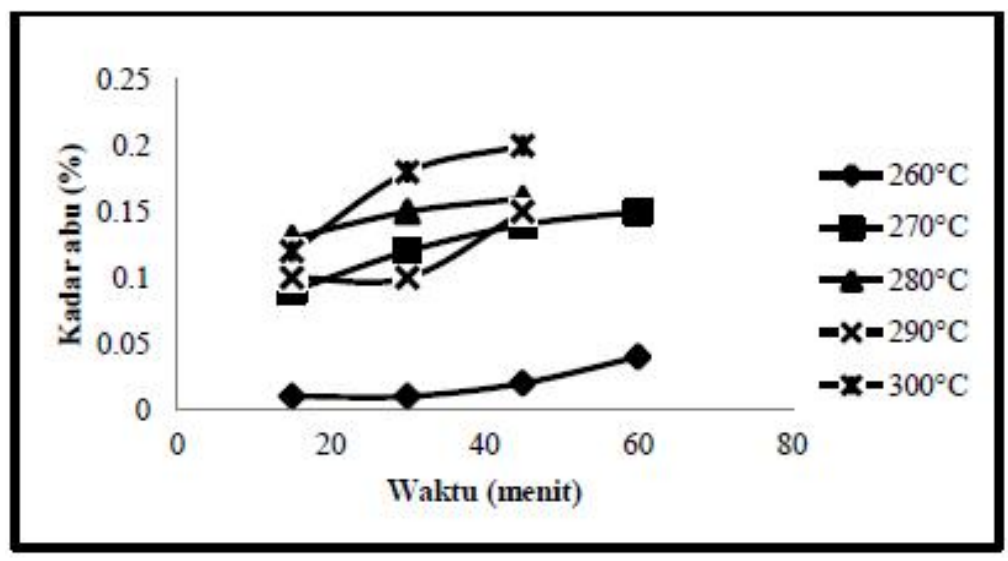

Gambar 3 Pengaruh suhu dan waktu pirolisis terhadap kadar abu

Hasil kadar abu yang didapat pada penelitian ini memang belum memenuhi standar mutu bahan bakar minyak, namun ada beberapa produk yang didapat sudah mendekati standar mutu bahan bakar minyak di Indonesia. Umumnya, standar mutu kadar abu bahan bakar minyak di Indonesia berada pada kisaran 0,03-0,7\% (Tjokrowisastro, 1990).

\subsection{Pengaruh suhu dan waktu pirolisis terhadap kadar air}

Kadar air merupakan sifat fisis yang menunjukkan kandungan air pada bahan bakar dalam keadaan setimbang dengan lingkungan sekitarnya. Penentuan kadar air atau analisa kadar air bertujuan untuk mengetahui seberapa besar persentase air pada sampel produk. Data hasil pengujian kadar air untuk bahan bakar minyak dari dari limbah kantong plastik jenis kresek ditunjukkan pada Gambar 4.

Gambar 4 menunjukkan bahwa kadar air pada produk bahan bakar minyak dari limbah kantong plastik jenis kresek semakin menurun, kadar air paling tinggi adalah pada suhu pirolisis $260^{\circ} \mathrm{C}$ waktu reaksi 15 menit yaitu $0,53 \%$ dan kadar air paling rendah pada suhu pirolisis tertinggi $300^{\circ} \mathrm{C}$ waktu reaksi 60 menit yaitu $0,01 \%$. Gambar diatas bisa dilihat semakin tinggi suhu pirolisis maka semakin sedikit kadar air yang diperoleh. Hal ini disebabkan oleh banyaknya kadar air 
yang hilang pada suhu yang semakin tinggi. Beberapa produk bahan bakar minyak yang didapatkan sudah memenuhi standar mutu bahan bakar minyak di Indonesia yang memiliki kandungan air maksimal sebesar 0,05\% (Dirjen Migas, 2004). Kadar air dalam bahan bakar minyak merupakan salah satu tolak ukur mutu bahan bakar minyak tersebut. Semakin kecil kadar air dalam bahan bakar minyak maka mutunya akan semakin baik, karena air adalah penyebab keharusan pada sistem pompa bakarnya (Tjokrowisastro, 1990).

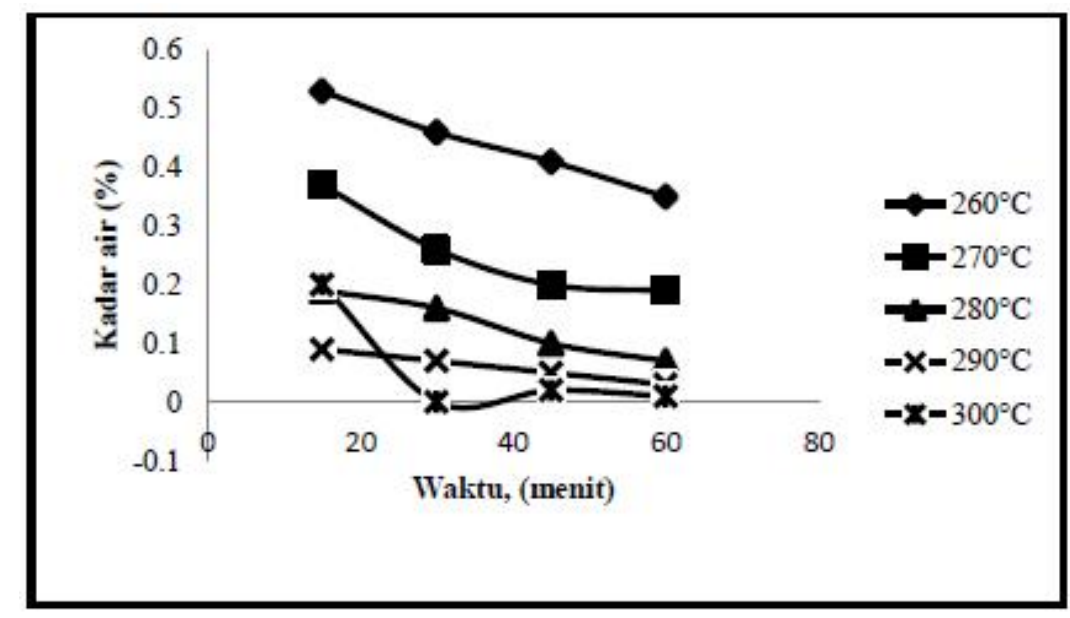

Gambar 4 Pengaruh suhu dan waktu pirolisis terhadap kadar air

\subsection{Analisa komposisi kimia}

Bahan bakar minyak limbah kantong plastik jenis kresek yang sudah didistilasi selanjutnya dianalisa dengan menggunakan alat Gas CromatografiMass Spektrofotometer (GC-MS) untuk mengetahui komposisi dari bahan bakar minyak. Pengujian GC-MS mengidentifikasi beberapa komponen dari bahan bakar minyak tersebut, hasil analisa GC-MS menunjukkan 11 komposisi yang terdapat pada bahan bakar minyak dari limbah kantong plastik jenis kresek. Komposisi tersebut terdiri dari $\mathrm{C}_{12} \mathrm{H}_{24}$ sebanyak $29,3 \%, \mathrm{C}_{7} \mathrm{H}_{8}$ sebanyak $16,1 \%$, $\mathrm{C}_{8} \mathrm{H}_{10}$ sebanyak 15,6\%, $\mathrm{C}_{15} \mathrm{H}_{30}$ sebanyak 5,9\%, $\mathrm{C}_{14} \mathrm{H}_{30}$ sebanyak 9,6\%, $\mathrm{C}_{11} \mathrm{H}_{22}$ sebanyak $13,9 \%$ dan $\mathrm{C}_{8} \mathrm{H}_{8}$ sebanyak 9,14\%. Hasil analisa GC-MS dapat dilihat pada Gambar 5. 


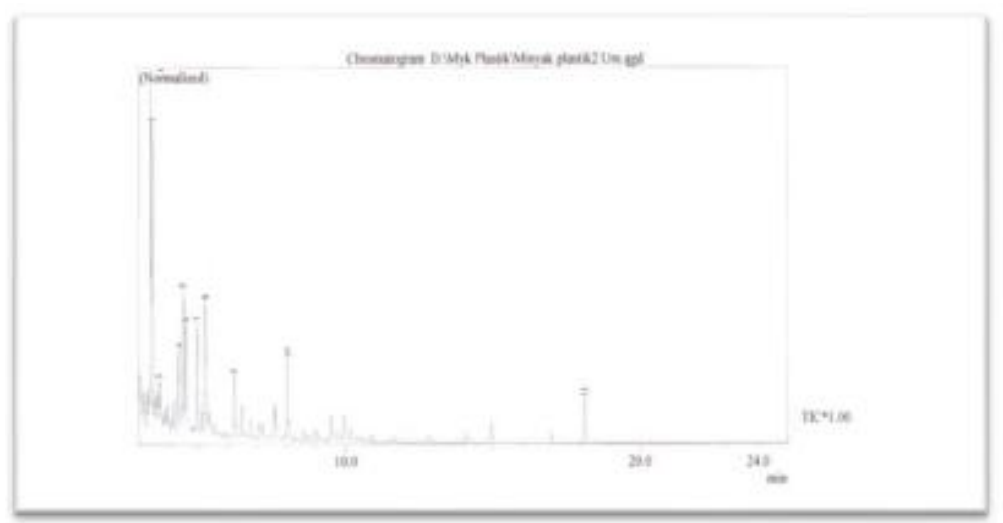

Gambar 5 Kromatogram analisa komposisis

\section{Simpulan}

1. Berdasarkan penelitian yang telah dilakukan maka dapat diambil kesimpulan bahwa nilai kalor yang diperoleh dari hasil perhitungan komposisi kimianya sebesar $10.541,75 \mathrm{kkal} / \mathrm{kg}$.

2. Titik nyala dari beberapa sampel produk yang didapatkan memenuhi standar mutu bahan bakar minyak di Indonesia, diantaranya yang paling mendekati titik minimum pada suhu pirolisis $300^{\circ} \mathrm{C}$ yaitu $57,5^{\circ} \mathrm{C}$.

3. Semakin tinggi suhu pirolisis maka semakin sedikit kadar air yang diperoleh yaitu berkisar antara 0,01-0,53\%.

4. Semakin tinggi suhu pirolisis maka semakin banyak pula kadar abu yang dihasilkan, di mana hasil tertinggi yang diperoleh dalam penelitian ini adalah pada suhu pirolisis $300^{\circ} \mathrm{C}$ yaitu $0.26 \%$ dan yang terendah pada suhu pirolisis $260^{\circ} \mathrm{C}$ yaitu $0,01 \%$.

\section{Daftar Pustaka}

Aprian Ramadhan, 2012, pengolahan sampah plastik jenis High Density Polyethylene (HDPE) dan Low Density Polyethylene (LDPE) menjadi minyak menggunakan proses pirolisis.

Anonimous, 2005, Wood-plastics Composites: Current trent in material and processing, Plastic additives \& Compounding, September/October edition. 
BLHK dan DPKP, 2014, Lhokseumawe Dalam Angka 2014, Pemerintah Kota Lhokseumawe.

Affendi, 2008, "Karakteristik Bahan Bakar Cair", Penelitian Nilai Kalor Bahan Bakar, Institut Teknologi Sepuluh Nopember.

Hadiwiyoto S., 2000, Penanganan dan Pemanfaatan Sampah, Yayasan Idayu Jakarta.

Harper dan Charles A., 1999. Modern Plastic Handbook, McGraw-Hill.

Matar dan Lewis, 2000, Chemistry Of Petrochemichal Process, 2nd edition Houstoun: Texas, US.

Puspita, 2013. Informasi Energi Indonesia, Jurusan Teknik Lingkungan FTSP UPN "Veteran" Jatim

Ramsay W. S., 1982, Energy From Forest Biomass, Ed. Academic Press, Inc, New York.

Rodiansono, Trisunaryanti, W., dan Triyono, 2007, Pembuatan dan Uji Aktivitas Katalis NiMo/Z pada Reaksi Hidrorengkah Fraksi Sampah Plastik menjadi Fraksi Bensin, Berkala MIPA,17,2.

Sumarni, 2008, Kinetika Reaksi Pirolisis Plastik Low Density Poliethylene $(L D P E)$, Jurusan Teknik Kimia, Institut Sains dan Teknologi AKPRIND Yogyakarta.

Syafitri dkk, 2001, Pengelolaan Limbah Plastik Dengan Metode Recycle. Jurusan Teknik Lingkungan FTSP UPN "Veteran” Jatim.

Tjokrowisastro,E.H., dkk, 1990, "Teknik Pembakaran Dasar dan Bahan Bakar", Diktat ITS-Surabaya.

Wardani, 2009, Bahaya Penggunaan Sampah Plastik, Tesis FKIP, MIPA Universitas Palangkaraya.

Wahyudi,I.,2001."Pemanfaata Plastik menjadi Bahan Bakar Cair dengan Proses Pirolisis". Jurusan Teknik Lingkungan FTSP UPN Veteran, Jatim.

Young J.F., Mindess S., Bentur A., 1993, The Science and Technology of Civil Engineering Material, Prentice Hall. 